\title{
Análise de manuais de testes psicológicos aprovados pelo Satepsi para avaliação de adultos
}

Caroline Tozzi Reppold'

Universidade Federal de Ciências da Saúde de Porto Alegre - UFCSPA, RS, Brasil

Adriana Jung Serafini

Universidade Federal de Ciências da Saúde de Porto Alegre - UFCSPA, RS, Brasil

Léia Gonçalves Gurgel

Universidade Federal de Ciências da Saúde de Porto Alegre - UFCSPA, RS, Brasil

Emília dos Santos Magnan

Universidade Federal de Ciências da Saúde de Porto Alegre - UFCSPA, RS, Brasil

Marina Damion

Universidade Federal de Ciências da Saúde de Porto Alegre - UFCSPA, RS, Brasil

Vanessa Kaiser

Universidade Federal de Ciências da Saúde de Porto Alegre - UFCSPA, RS, Brasil

Leandro da Silva Almeida

Universidade do Minho - UM, Braga, Portugal

\begin{abstract}
Resumo: Neste artigo, os manuais de testes psicológicos considerados favoráveis pelo Satepsi para avaliação, em adultos, de personalidade, atributos emocionais/sociais ou aspectos profissionais/laborais foram analisados em relação à indicação de uso, autoria, editora, estudos normativos e construtos cobertos. Dos 173 testes listados no Satepsi em julho de 2017, 65 foram incluídos: 33 destinados à avaliação de personalidade (19 escalas/inventários e 14 testes projetivos), 20 voltados à avaliação de atributos emocionais/sociais e 12 relacionados à orientação profissional ou ao contexto laboral. A maioria dos testes apresenta em seus manuais as informações investigadas. Apesar de haver, em alguns casos, discrepâncias entre a indicação de uso do teste e a idade das amostras de normatização brasileira, os achados levam à conclusão de que a qualidade das informações consultadas nos manuais representa um avanço em relação ao panorama descrito por pesquisadores da área nas décadas de 1990 e 2000.
\end{abstract}

Palavras-chave: testes psicológicos; avaliação psicológica; personalidade; ajustamento emocional; carreira.

\section{ANALYSIS OF PSYCHOLOGICAL TEST MANUALS APPROVED BY SATEPSI FOR} ADULT ASSESSMENT

Abstract: In this article, the psychological test manuals considered favorable by Satepsi to assessment of personality, emotional/social attributes or professional/work-related aspects in adults were analyzed in relation to the indication of use, authorship, publisher, normative studies and constructs. Of the 173 tests listed in the Satepsi in July 20I7, 65 were included: 33 are intended for personality assessment (19 scales/inventories and

${ }^{1}$ Endereço de correspondência: Caroline Reppold: Laboratório de Pesquisa em Avaliação Psicológica, sala 117 Anexo II, Universidade Federal de Ciências da Saúde de Porto Alegre, Rua Sarmento Leite, 24.5, Porto Alegre, RS. CEP: 90500-170. E-mail: carolinereppold@yahoo.com.br 
14 projective tests), 20 to assessment of emotional/social attributes and 12 related to professional orientation or work context. Most of the tests present in their manuals the information investigated. Although there are in some cases discrepancies between the indication of use of the test and the age of Brazilian standardization samples, the data lead to the conclusion that the quality of the information consulted in the manuals represents an advance in relation to the panorama described by researchers of the area in the 1990s and 2000s.

Keywords: psychological tests; psychological assessment; personality; emotional adjustment; career.

ANÁLISIS DE MANUALES DE PRUEBAS PSICOLÓGICAS APROBADOS POR EL SATEPSI PARA EVALUACIÓN DE ADULTOS

\begin{abstract}
Resumen: En este artículo, los manuales de pruebas psicológicas consideradas favorables por el Satepsi para evaluación, en adultos, de personalidad, atributos emocionales/ sociales o factores profesionales/laborales fueron analizados en relación a la indicación de uso, autoría, editora, estudios normativos y construcciones. De los 173 tests listados en el Satepsi en julio de 2017, 65 fueron incluidos: 33 destinados a la evaluación de personalidad ( 19 escalas/inventarios y 14 pruebas proyectivas), 20 a la evaluación de atributos emocionales/sociales y 12 relacionados a la orientación profesional o al contexto laboral. La mayoría de las pruebas presentan en sus manuales la información investigada. A pesar de haber, en algunos casos, discrepancias entre la indicación de uso y la edad de las muestras de normatización brasileña, los datos evidencian que la calidad de la información de los manuales representa un avance en relación al panorama descrito por investigadores del área en las décadas de 1990 y 2000.
\end{abstract}

Palabras clave: pruebas psicológicas; evaluación psicológica; personalidad; ajuste emocional; carrera.

\title{
Introdução
}

A avaliação psicológica (AP) é um procedimento técnico-científico realizado exclusivamente por um(a) psicólogo(a) e configura-se como uma das mais importantes e frequentes atividades profissionais exercidas na Psicologia (Ambiel, Pereira, \& Moreira, 2015; Diniz, Almeida, \& Pais, 2007). Trata-se de processo, muitas vezes, complexo (Hutz, 2015; Hunsley \& Mash, 2007) que tem o intuito de avaliar fenômenos psicológicos de forma empírica e contextualizada, considerando condicionantes históricos e sociais e o caráter dinâmico do psiquismo humano (Urbina, 2007; Reppold \& Serafini, 2010; Conselho Federal de Psicologia, 2013). Geralmente envolve o uso de variadas fontes de informações, entre as quais instrumentos psicológicos, instrumentos não psicológicos, técnicas de entrevistas, técnicas de observação e/ou análise de documentos. Desses, os testes psicológicos são alguns dos recursos mais utilizados na prática avaliativa, pois se configuram como um meio padronizado para obtenção de respostas que representam uma amostra de comportamento (Allen \& Yen, 2012; International Test Commission, 2013), viabilizando, assim, a observação, o registro e a descrição/ mensuração de aspectos que permitam fazer inferências sobre determinado construto psicológico - um fenômeno não observado diretamente. De acordo com a Resolução n. 005/2012 do Conselho Federal de Psicologia (CFP), para que sejam reconhecidos como testes psicológicos em condições de uso, os instrumentos deverão atender aos 
Caroline Tozzi Reppold, Adriana Jung Serafini, Léia Gonçalves Gurgel, Emília dos Santos Magnan, Marina Damion,

Vanessa Kaiser, Leandro da Silva Almeida

requisitos técnicos e científicos definidos na Resolução CFP n. 002/2003, bem como a requisitos éticos e de defesa dos direitos humanos dispostos no documento. Tais requisitos técnicos e científicos abrangem, entre outros aspectos, indicadores de precisão e de validade, bem como um sistema de correção e interpretação de dados fundamentados teórica e empiricamente.

A análise desses requisitos é uma das tarefas da Comissão Consultiva de Avaliação Psicológica (CCAP) do CFP. Essa comissão é formada por pesquisadores e conselheiros com experiência e produção científica na área da AP e foi instituída pela Resolução CFP n. 002/2003. Especificamente, o artigo $4^{\circ}$ dessa resolução determina que os testes submetidos à CCAP sejam avaliados de acordo com os seguintes requisitos:

I - apresentação da fundamentação teórica do instrumento, com especial ênfase na definição do construto [...];

II - apresentação de evidências empíricas de validade e precisão das interpretações propostas para os escores do teste [...];

III - apresentação de dados empíricos sobre as propriedades psicométricas dos itens do instrumento;

IV - apresentação do sistema de correção e interpretação dos escores, explicitando a lógica que fundamenta o procedimento, em função do sistema de interpretação adotado, que pode ser: a) referenciado à norma, devendo, nesse caso, relatar as características da amostra de padronização de maneira clara e exaustiva, preferencialmente comparando com estimativas nacionais, possibilitando o julgamento do nível de representatividade do grupo de referência usado para a transformação dos escores, b) diferente da interpretação referenciada à norma, devendo, nesse caso, explicar o embasamento teórico e justificar a lógica do procedimento de interpretação utilizado.

V - apresentação clara dos procedimentos de aplicação e correção, bem como as condições nas quais o teste deve ser aplicado, para que haja a garantia da uniformidade dos procedimentos envolvidos na sua aplicação;

VI - compilação das informações indicadas acima, bem como outras que forem importantes [...] (Conselho Federal de Psicologia, 2003, p. 2-3).

Tais requisitos são considerados nos casos dos testes objetivos e também nos testes projetivos. Contudo, na avaliação dos testes projetivos, a apresentação de dados empíricos sobre suas propriedades psicométricas é avaliada de acordo com as especificidades típicas desses instrumentos. A verificação técnica do cumprimento desses requisitos é realizada inicialmente por pareceristas ad hoc da CCAP e, a seguir, pela comissão, que elabora um parecer a ser enviado para decisão da plenária do CFP. De acordo com o artigo $9^{\circ}$ da Resolução n. 002/2003 do CFP, a avaliação será favorável quando, por decisão da plenária, o teste é considerado em condições de uso ou desfavorável quando a análise indicar que o instrumento não apresenta as condições mínimas para uso. A partir de então, a utilização de um teste psicológico que conste na relação dos instrumentos considerados desfavoráveis pelo CFP será considerada falta ética, salvo quando utilizado em situações de pesquisa. 
Ao apresentar essas normativas, o CFP tem empregado esforços para qualificar os testes psicológicos disponíveis no Brasil e informar os psicólogos e a comunidade a esse respeito. As orientações propostas pelo CFP decorrem de standards de instituiçõos científicas internacionais, em particular os estabelecidos em consenso em torno da International Test Commission (ITC) ou do consórcio formado pela American Educational Research Association, American Psychological Association, National Council on Measurement in Education. Um dos mecanismos utilizados pelo Sistema de Avaliação de Testes Psicológicos (Satepsi) para esse propósito é a divulgação pública de uma lista, no site do CFP, de quais testes são considerados aprovados para uso profissional por parte dos psicológicos. Essa publicidade é determinada pelo artigo 15 da Resolução n. 002/2003.

O resultado desses esforços pode ser observado na progressiva qualificação das informações contidas nos manuais dos testes psicológicos ao longo das últimas décadas, bem como no número de testes que passaram a ser considerados não aprovados para uso profissional ao longo dos 15 anos de funcionamento do Satepsi, por não atingirem critérios mínimos de qualidade técnico-científica. Ao apresentar dados relativos à política do CFP para área de AP entre 2003 e 2010, Anache e Correa (2010) informam que, nesse período, o Satepsi recebeu 210 testes para análise, dos quais 77 não preenchiam os critérios mínimos da Resolução n. 002/2003, obtendo, assim, parecer desfavorável para uso profissional.

De fato, pesquisas publicadas antes de 2003 revelavam a precariedade dos manuais e dos instrumentos que eram utilizados naquele momento, bem como o despreparo técnico dos estudantes e profissionais em relação ao uso dos testes psicológicos ou aos seus fundamentos científicos e deontológicos (Noronha, Sartori, Freitas, \& Ottati, 2001, 2002; Noronha, Beraldo, \& Oliveira, 2003; Noronha, 2002b). O estudo de Noronha (2002a) sobre a qualidade das informações contidas nos manuais dos testes de personalidade disponíveis no Brasil até então demonstrou que a maioria dos testes eram instrumentos importados, alguns isentos de estudos com amostras nacionais e datados da década de 1920, sem atualizações. O artigo concluiu que a pesquisa brasileira da área de AP na época era ainda incipiente e "desanimadora, pois revela(va) uma pequena produção no espaço de aproximadamente sete décadas" (Noronha, 2002a, p. 63), considerando o período de 1930 a 2000.

Investigando também informações contidas em manuais de testes de personalidade, Noronha et al. (2001) avaliaram a presença ou ausência das seguintes informações nos manuais: nome do autor, editor e data de publicação do manual em português, variável medida, áreas de aplicação, formato e número dos itens, suporte, correção, transformação da pontuação, escala utilizada, tempo de aplicação, documentação fornecida e bibliografia utilizada. Dos 22 manuais consultados, apenas dez apresentavam todas as informações analisadas. Os autores, ao discutirem os resultados, apontaram na ocasião:

Não parece mais novidade que testes sejam publicados sem que os manuais apresentem as informações necessárias para uma utilização adequada e satisfatória. Manuais sem data, com a ausência do nome 
Caroline Tozzi Reppold, Adriana Jung Serafini, Léia Gonçalves Gurgel, Emília dos Santos Magnan, Marina Damion,

Vanessa Kaiser, Leandro da Silva Almeida

do autor ou do editor, sem a consistente fundamentação teórica, sem as informações das pesquisas de padronização, ou ainda, sem informações sobre validade e precisão, infelizmente não são incomuns (Noronha et al., 2001, p. 148).

Noronha, Freitas e Ottati (2003) realizaram estudo com propósito semelhante, mas considerando a avaliação de oito instrumentos até então disponíveis para avaliação de processos de orientação profissional. Os resultados não foram muito diferentes. Os autores concluíram que dois dos oito testes analisados descreviam, em seus manuais, informações pertinentes à padronização, à validade e à precisão, três apresentam apenas dados sobre dois dos aspectos e três não apresentam quaisquer das informações estudadas.

Esses dados vão ao encontro das considerações de Pasquali (1999) sobre o estado da arte da AP no Brasil, no final do século passado, antes da criação do Satepsi. Pasquali (1999) avaliava que a maior parte dos pesquisadores brasileiros estava voltada, na época, para utilização de testes estrangeiros, sem preocupar-se com a aferição da qualidade psicométrica desses instrumentos ou com a aplicabilidade deles na cultura local. Isso é o que revelava também o estudo publicado por Noronha, Primi e Alchieri (2004), que realizou uma análise dos parâmetros psicométricos de 146 testes comercializados no Brasil até 2003 por 11 editoras. Os resultados indicaram que apenas 28,8\% dos instrumentos comercializados até a data apresentavam estudos de precisão, validade e padronização. Considerando apenas dados de precisão e validade, 41,8\% dos testes apresentavam essas informações. Nessa verificação, não foi discriminado se se tratava de estudos nacionais ou estrangeiros. Dessa feita, caso fosse considerada a exigência de estudos nacionais nos manuais, os resultados de Noronha et al. (2004) seriam ainda menores. A análise desses dados levou os pesquisadores a concluir que parte expressiva dos instrumentos comercializados até 2003 carecia de fundamentação científica e não atendia aos requisitos mínimos definidos pelo CFP ou pelos padrões internacionais da área. De acordo com os autores do artigo, a publicação da Resolução CFP n. 002/2003 e a criação do Satepsi configuravam-se, na ocasião, como uma importante medida para qualificação dos instrumentos da área e para atenção à necessidade de formação continuada dos psicólogos brasileiros.

$\mathrm{Na}$ prática, as evidências indicaram que os esforços do Satepsi em implementar ações de melhoria na área da AP surtiram efeitos diretos e indiretos. Artigos publicados por Noronha e Reppold (2010), Primi (2010) e Santos, Anache e Santana (2015) apresentam um panorama sobre o desenvolvimento da AP no Brasil nas últimas décadas e destacam a expansão dos grupos de pesquisa vinculados à área, o aumento no número de programas de pós-graduação específicos do campo da AP e maior preocupação em relação à qualidade do ensino de fundamentos, conceitos e técnicas da AP. Uma das evidências mais objetivas das consequências do Satepsi foi o aumento do número da publicação de estudos empíricos relacionados ao desenvolvimento de instrumentos psicológicos, sobretudo no período entre 2003 e 2008 (Santos et al., 2015). 
A implementação do Satepsi fez do Brasil um dos países pioneiros na criação e implementação de um sistema de certificação dos instrumentos psicológicos baseado em critérios internacionais de qualidade (propostos pela American Educational Research Association, American Psychological Association, National Council on Measurement in Education) e estendido à avaliação de todos os instrumentos disponíveis para uso profissional por parte dos psicólogos (Primi, 2010). Esse feito tem sido reconhecido por órgãos internacionais vinculados à área, como a American Psychological Association Division 5 e a ITC (Hutz \& Primi, 2006). Contudo, atualmente, os dados disponibilizados pelo Satepsi em relação aos testes psicológicos limitam-se à divulgação das seguintes informações: título, autores, editora, data da recepção do instrumento pela CCAP, data da plenária do CFP no qual o parecer do teste foi julgado e o resultado final do julgamento pela plenária, indicando a situação do teste (favorável ou desfavorável) (http://satepsi.cfp.org.br/\#).

Informações relacionadas à indicação de uso, à fundamentação teórica do instrumento ou aos estudos de precisão, evidências de validade e normatização do instrumento ainda não são disponibilizadas no site do CFP. Desta feita, falta ao psicólogo uma catalogação sistemática de informações que possam auxiliá-lo a tomar decisões sobre a escolha dos testes psicológicos mais pertinentes em cada situação avaliativa. Exemplos de informações relevantes a serem consideradas nessa decisão são o construto coberto pelo instrumento, a indicação de uso do teste e a idade dos participantes nas amostras de normatização dos instrumentos no Brasil. Essa falta de informações é particularmente deletéria se considerada a dificuldade, econômica e logística, que muitos psicólogos têm em acessar os manuais físicos dos testes para obter informações que o auxiliem a planejar um processo avaliativo a partir de critérios técnico-científicos. Duas publicações recentes buscam minizar essas dificuldades. A primeira é o artigo publicado por Reppold, Serafini, Ramires e Gurgel (2017), que reúne os testes psicológicos aprovados pelo CFP para avaliação de crianças e adolescentes até os 18 anos de idade. A segunda é o artigo de Reppold, Serafini, Gurgel e Kaiser (2017), que investiga quais testes aprovados pelo Satepsi são destinados à avaliação de aspectos cognitivos em adultos. Nos dois casos, as publicações incluem informações a respeito da faixa etária para qual cada teste é indicado, o construto abordado pelos instrumentos e uma comparação entre a idade de indicação de uso e a idade das amostras de normatização de cada instrumento para a população brasileira. No entanto, permanecem as dificuldades para acessar informações a respeito dos demais instrumentos que compõem a lista dos testes avaliados favoravelmente pelo CFP. Diante dessa lacuna, o presente artigo foi desenvolvido com os seguintes objetivos:

- Verificar, entre o total de instrumentos considerados favoráveis no Satepsi, que percentual dos testes se destina à avaliação, em adultos, 1. de personalidade, 2. de atributos emocionais/sociais ou 3. de construtos relacionados à orientação/ao desenvolvimento profissional ou ao contexto laboral e a identificá-los. 
- Entre os instrumentos destinados à avaliação de personalidade em adultos e listados como favoráveis no Satepsi, identificar se o maior percentual é de testes em formato de inventários/escalas ou de testes projetivos.

- Investigar, a partir da data de aprovação do teste na plenária do CFP, quais instrumentos destinados à avaliação de adultos (para as áreas investigadas no estudo) foram aprovados nos últimos cinco anos.

- Entre os testes considerados de uso favorável pelo CFP para avaliação de personalidade, de atributos emocionais/sociais ou de aspectos relacionados à orientação/ ao desenvolvimento profissional ou ao contexto laboral, apresentar o percentual de manuais que possuem informações a respeito da idade das amostras dos estudos de normatização brasileira e investigar se a idade de indicação dos testes informada nos manuais está de acordo com a idade das amostras dos estudos brasileiros de normatização.

- Identificar quais são os construtos mais frequentemente cobertos pelos testes considerados favoráveis no Satepsi para avaliação de atributos emocionais/sociais em indivíduos adultos.

- Identificar quais são os construtos mais frequentemente cobertos pelos testes considerados favoráveis no Satepsi para avaliação de aspectos relacionados à orientação/ao desenvolvimento profissional ou ao contexto laboral.

- Identificar os autores com maior número de publicações de testes em cada categoria.

\section{Método}

Para a realização desta pesquisa, foi considerada a lista de testes psicológicos avaliados pela CCAP e considerados, por deliberação da plenária do CFP, favoráveis para uso profissional pelos psicólogos, publicada no site do Satepsi em 3 de julho de 2017 (http://satepsi.cfp.org.br/listaTesteFavoravel.cfm). Todos os testes listados pelo CFP como favoráveis foram incluídos na busca. O critério de inclusão dos testes neste estudo foi a idade de indicação do instrumento: todos os testes que eram indicados para uso em adultos foram incluídos, ainda que fossem também indicados para idades menores que 18 anos. O critério de exclusão dos testes no presente estudo foi o construto avaliado pelo teste: todos os testes que avaliavam construtos relacionados à inteligência ou outros processos cognitivos foram excluídos, por terem sido já objeto de estudo anterior (Reppold, Serafini, Gurgel et al., 2017).

De posse da lista do Satepsi e dos critérios de inclusão e exclusão desta pesquisa, os manuais dos testes considerados neste estudo foram analisados, de modo a obter as seguintes informações: título dos testes, autoria (identificação do autor ou autores da adaptação brasileira, quando era o caso), editora, construto(s) coberto(s) pelo teste, idade para qual o teste tem uso indicado, idade das amostras do(s) estudo(s) de normatização brasileira, data de aprovação do instrumento na plenária do CFP. O acesso às informações citadas deu-se 1. pela análise documental dos manuais dos testes disponíveis em lojas distribuidoras/revendedoras autorizadas de material privativo de 
psicólogos ou no acervo das testotecas de três universidades gaúchas; 2 . pela consulta a páginas on-line das editoras ou ao site do Satepsi; 3. por colaboração de pesquisadores; ou 4. pela consulta a manuais de testes disponibilizados pelo CFP. As informações não localizadas em nenhum desses meios foram descritas nos resultados como "sem acesso".

Os testes incluídos neste estudo foram classificados em três categorias: 1. testes destinados à avaliação de personalidade, 2 . testes destinados à avaliação de atributos emocionais/sociais e 3. testes destinados à avaliação de aspectos relacionados ao desenvolvimento/contexto profissional. Na primeira categoria, foram incluídos todos os testes cujos manuais informavam que o construto coberto pelo instrumento era personalidade. Na terceira categoria, foram incluídos os testes que avaliavam aspectos relacionados à orientação/escolha profissional, ao perfil/à adaptação profissional e ao contexto laboral. Na segunda categoria, todos os demais instrumentos que atendiam aos critérios de inclusão e não exclusão da amostra e que tiveram como característica comum a avaliação de algum atributo emocional/social do(s) indivíduos(s). Ressalta-se que as categorias propostas neste trabalho foram assim organizadas meramente por questões didáticas e não teóricas, já que os instrumentos que compõem cada categoria podem ser utilizados em diferentes contextos, a depender dos estudos de validade desenvolvidos. Nesse sentido, observa-se que a literatura da área não é coesa quanto à proposta de ter uma única taxonomia para classificação dos testes (Andrade \& Salles, 2017; Serafini, Budzyn, \& Fonseca, 2017). Enquanto alguns autores consideram os construtos avaliados ou a finalidade dos testes nessa classificação, outros consideram como critério de classificação o tipo de instrução que define a resposta ou as técnicas utilizadas para construção e aferição de seus parâmetros psicométricos. Em todos os casos, trata-se de classificações meramente didáticas, como é a proposta neste artigo, como já mencionado anteriormente. Em relação aos testes destinados à avaliação de personalidade, destaca-se, também, que, no presente artigo, eles foram ainda divididos em duas classes: testes de autorrelato e testes projetivos. Essa classificação vai ao encontro de publicações da área que preconizam o uso desses termos em lugar de "objetivos" e "projetivos", considerados teoricamente inadequados por terem embutida a ideia de que testes projetivos não envolvem critérios objetivos de avaliação (Meyer \& Kurtz, 2006; Bornstein, 2007; Wagner, 2008; Cardoso \& Villemor-Amaral, 2017).

\section{Resultados}

Na data em que a lista dos testes considerados favoráveis pelo CFP foi consultada, lá constavam 173 testes. Considerando os critérios de inclusão e exclusão da amostra para o presente estudo, 65 testes foram selecionados. Esses testes eram destinados à avaliação de personalidade, de atributos emocionais/sociais ou de atributos relacionados à escolha profissional/ao desenvolvimento de carreira. Esse número corresponde a $37,6 \%$ do total de 173 instrumentos que compunham a lista dos testes aprovados para uso profissional por parte dos psicólogos. 
Dos instrumentos aprovados para uso profissional pelo Satepsi/CFP em julho de 2017 ( $n=173$ ), 33 testes eram destinados à avaliação do construto personalidade, o que corresponde a 19,1\% da lista. Desses testes, 19 (11\% do total de testes favoráveis) caracterizavam-se como testes psicométricos em formato de inventário ou escala e $14(8,1 \%)$ como testes projetivos. O Quadro 1, referente às escalas ou aos inventários que avaliam personalidade, apresenta as seguintes informações desses instrumentos: título do teste, autoria, editora, idade de indicação do uso do teste segundo o manual, idade das amostras de normatização do teste para população brasileira e data da reunião plenária do CFP na qual o instrumento foi aprovado. O quadro também revela quais dos instrumentos estão baseados teoricamente no modelo dos Cinco Grandes Fatores para avaliação da personalidade.

\section{Quadro I. Informações dos testes de personalidade, em formato de escala ou inventário, considerados favoráveis pelo CFP para avaliação de adultos (n = 19).}

\begin{tabular}{|c|c|c|c|c|c|}
\hline Nome do teste' & Autores $^{2}$ & Editora $^{3}$ & $\begin{array}{l}\text { Idade } \\
\text { indicada }\end{array}$ & $\begin{array}{l}\text { Idade da amostra } \\
\text { normativa }^{4}\end{array}$ & $\begin{array}{l}\text { Data da } \\
\text { plenária }\end{array}$ \\
\hline $\begin{array}{l}\text { Bateria Fatorial de } \\
\text { Personalidade - BFP* }\end{array}$ & $\begin{array}{l}\text { Carlos Henrique } \\
\text { Nunes, Claudio Hutz \& } \\
\text { Maiana Nunes }\end{array}$ & $\begin{array}{l}\text { Casa do Psicólogo/ } \\
\text { Pearson }\end{array}$ & $\begin{array}{l}\text { Adolescentes } \\
\text { e adultos }\end{array}$ & De 10 a 75 anos & I.8.2009 \\
\hline $\begin{array}{l}\text { Escala de Avaliação } \\
\text { Tipológica - EAT }\end{array}$ & Emanuel Tadei & Asserthy & $\begin{array}{l}\text { De } 13 \text { a } \\
63 \text { anos }\end{array}$ & De 13 a 63 anos & 3.12 .2011 \\
\hline $\begin{array}{l}\text { Escala de Personalidade } \\
\text { de Comrey - CPS }\end{array}$ & Flavio Costa & Vetor & $\begin{array}{l}\text { A partir de } \\
18 \text { anos }\end{array}$ & $\begin{array}{l}\text { Acima de } \\
18 \text { anos }\end{array}$ & 25.10 .2003 \\
\hline $\begin{array}{l}\text { Escala Fatorial de } \\
\text { Ajustamento Emocional/ } \\
\text { Neuroticismo - EFN* }\end{array}$ & $\begin{array}{l}\text { Carlos Henrique } \\
\text { Nunes \& Claudio Hutz }\end{array}$ & $\begin{array}{l}\text { Casa do Psicólogo/ } \\
\text { Pearson }\end{array}$ & $\begin{array}{l}\text { De } 16 \text { a } \\
50 \text { anos }\end{array}$ & $\begin{array}{l}\text { De } 16 \text { a "28 anos } \\
\text { ou mais" }\end{array}$ & II .4 .2003 \\
\hline $\begin{array}{l}\text { Escala Fatorial de } \\
\text { Extroversão - EFEx* }\end{array}$ & $\begin{array}{l}\text { Carlos Henrique } \\
\text { Nunes \& Claudio Hutz }\end{array}$ & $\begin{array}{l}\text { Casa do Psicólogo/ } \\
\text { Pearson }\end{array}$ & $\begin{array}{l}\text { De } 14 \text { a } \\
55 \text { anos }\end{array}$ & De 14 a 55 anos & 30.3.2007 \\
\hline $\begin{array}{l}\text { Escala Fatorial de } \\
\text { Socialização - EFS* }\end{array}$ & $\begin{array}{l}\text { Carlos Henrique } \\
\text { Nunes \& Claudio Hutz }\end{array}$ & $\begin{array}{l}\text { Casa do Psicólogo/ } \\
\text { Pearson }\end{array}$ & $\begin{array}{l}\text { De } 14 \text { a } \\
64 \text { anos }\end{array}$ & De 14 a 64 anos & I.I2.2006 \\
\hline Escala HARE PCL-R ${ }^{5}$ & Hilda Morana & $\begin{array}{l}\text { Casa do Psicólogo/ } \\
\text { Pearson }\end{array}$ & $\begin{array}{l}\text { De } 16 \text { a } \\
51 \text { anos }\end{array}$ & De 16 a 51 anos & 2.12 .2005 \\
\hline HumanGuide & $\begin{array}{l}\text { Giselle Müller-Roger } \\
\text { Welter }\end{array}$ & Vetor & $\begin{array}{l}\text { De } 18 \text { a } \\
60 \text { anos }\end{array}$ & De 18 a 60 anos & 24.4.2009 \\
\hline $\begin{array}{l}\text { Inventário de } \\
\text { Personalidade NEO } \\
\text { Revisado - NEO PI-R* }\end{array}$ & $\begin{array}{l}\text { Carmem Flores- } \\
\text {-Mendoza, Ricardo } \\
\text { Primi, Elisabeth do } \\
\text { Nascimento, \& Carlos } \\
\text { Henrique Nunes }\end{array}$ & Vetor & $\begin{array}{l}\text { De } 18 \text { a } \\
60 \text { anos }\end{array}$ & De 16 a 74 anos & II.4.2008 \\
\hline $\begin{array}{l}\text { Inventário de Cinco } \\
\text { Fatores NEO Revisado - } \\
\text { NEO FFI-R (versão } \\
\text { curta)* }\end{array}$ & $\begin{array}{l}\text { Carmem Flores- } \\
\text {-Mendoza, Ricardo } \\
\text { Primi, Elisabeth do } \\
\text { Nascimento, \& Carlos } \\
\text { Henrique Nunes }\end{array}$ & Vetor & $\begin{array}{l}\text { De } 18 \text { a } \\
60 \text { anos }\end{array}$ & De 16 a 74 anos & II.4.2008 \\
\hline
\end{tabular}




\section{Quadro I. Informações dos testes de personalidade, em formato de escala ou inventário, considerados favoráveis pelo CFP para avaliação de adultos $(n=19)$.}

(conclusão)

\begin{tabular}{|c|c|c|c|c|c|}
\hline Nome do teste' & Autores $^{2}$ & Editora $^{3}$ & $\begin{array}{l}\text { Idade } \\
\text { indicada }\end{array}$ & $\begin{array}{l}\text { Idade da amostra } \\
\text { normativa }\end{array}$ & $\begin{array}{l}\text { Data da } \\
\text { plenária }\end{array}$ \\
\hline $\begin{array}{l}\text { Inventário de Tipos } \\
\text { Psicológicos - MBTI }\end{array}$ & Gleiber Couto & $\begin{array}{l}\text { Fellipelli } \\
\text { Instrumentos de } \\
\text { Diagnóstico e } \\
\text { Desenvolvimento } \\
\text { Organizacional }\end{array}$ & $\begin{array}{l}\text { De } 18 \text { a } \\
65 \text { anos }\end{array}$ & Sem acesso & 31.1 .2013 \\
\hline $\begin{array}{l}\text { Inventário dos Cinco } \\
\text { Fatores de Personalidade } \\
\text { Revisado - ICFP-R* }\end{array}$ & $\begin{array}{l}\text { Bartholomeu Tróccoli, } \\
\text { Luiz Pasquali, \& } \\
\text { Tatiana Severina } \\
\text { de Vasconcelos }\end{array}$ & LabPAM & $\begin{array}{l}\text { De } 16 \text { a } \\
74 \text { anos }\end{array}$ & Sem acesso & I7.4.2004 \\
\hline $\begin{array}{l}\text { Inventário dos } \\
\text { Seis Fatores de } \\
\text { Personalidade - IFP-6 }\end{array}$ & Luiz Pasquali & LabPAM & $\begin{array}{l}\text { Adolescentes } \\
\text { e adultos }\end{array}$ & De 16 a 93 anos & 29.4 .2017 \\
\hline $\begin{array}{l}\text { Inventário Fatorial de } \\
\text { Personalidade - IFP-II }\end{array}$ & $\begin{array}{l}\text { Irene Leme, Ivan } \\
\text { Rabelo, \& Gisele Alves }\end{array}$ & $\begin{array}{l}\text { Casa do Psicólogo/ } \\
\text { Pearson }\end{array}$ & $\begin{array}{l}\text { De } 14 \text { a } \\
86 \text { anos }\end{array}$ & De 14 a 86 anos & 24.5 .2013 \\
\hline $\begin{array}{l}\text { Inventário Fatorial de } \\
\text { Personalidade Revisado - } \\
\text { Forma Reduzida - IFP-R }\end{array}$ & $\begin{array}{l}\text { Luiz Pasquali, } \\
\text { Bartholomeu Tróccoli, } \\
\text { \& Robson de Araújo }\end{array}$ & LabPAM & $\begin{array}{l}\text { A partir de } \\
16 \text { anos }\end{array}$ & $\begin{array}{l}16 \text { até "acima de } \\
40 \text { anos" }\end{array}$ & 22.3 .2014 \\
\hline $\begin{array}{l}\text { Inventário Hogan de } \\
\text { Personalidade - HPI* }\end{array}$ & $\begin{array}{l}\text { Gleiber Couto \& } \\
\text { André Holer }\end{array}$ & $\begin{array}{l}\text { Ateliê RH } \\
\text { Desenvolvimento } \\
\text { Humano e } \\
\text { Organizacional }\end{array}$ & Adultos & $\begin{array}{l}\text { "Abaixo de } 30 \\
\text { anos" até "acima } \\
\text { de } 50 \text { anos" }\end{array}$ & 27.6 .2015 \\
\hline $\begin{array}{l}\text { Lista de Adjetivos } \\
\text { Bipolares e em Escalas } \\
\text { de Likert - L.A.B.E.L. }\end{array}$ & $\begin{array}{l}\text { Francis Gendre, } \\
\text { Roland Capel e } \\
\text { Renzo Oswald }\end{array}$ & $\begin{array}{l}\text { Moityca Eficiência } \\
\text { Empresarial }\end{array}$ & Adultos & Sem acesso & I5.10.2004 \\
\hline $\begin{array}{l}\text { Questionário de Avaliação } \\
\text { Tipológica - QUATI }\end{array}$ & José Jorge Zacharias & Vetor & $\begin{array}{l}\text { Adolescentes } \\
\text { e adultos }\end{array}$ & De 18 a 34 anos & 25.10 .2003 \\
\hline SOSIE $2^{\mathrm{a}}$ Geração & $\begin{array}{l}\text { Ricardo Primi, Acácia } \\
\text { dos Santos, Fabián } \\
\text { Rueda, Maria Nakano, } \\
\text { \& Alexandre Serpa }\end{array}$ & $\begin{array}{l}\text { Casa do Psicólogo/ } \\
\text { Pearson }\end{array}$ & Adultos & De 18 a 65 anos & 23.8 .2014 \\
\hline
\end{tabular}

O asterisco indica quais dos testes listados utilizam o modelo dos Cinco Grandes Fatores como fundamentação teórica.

' Alguns dos testes listados no quadro avaliam, além de personalidade, outros construtos ou indicadores.

${ }^{2}$ Embora alguns dos testes listados sejam instrumentos originalmente internacionais, as informações apresentadas no artigo referem-se aos autores dos estudos brasileiros de tradução, adaptação, validação e/ou normatização do teste psicológico em questão.

${ }^{3}$ Considerando o caráter didático do artigo e o fato de que algumas editoras foram incorporadas nos últimos anos, os quadros do artigo, em alguns casos, informam a editora do teste no Brasil na ocasião da sua aprovação e a editora na qual é atualmente comercializado.

${ }^{4}$ Alguns manuais não informam os limites mínimo e máximo da idade da amostra, apenas categorias de faixas etárias consideradas nas análises de normatização.

${ }^{5}$ Todos os testes listados no Quadro I são instrumentos psicométricos caracterizados como testes de personalidade de autorrelato, à exceção da Escala HARE PCL-R, que é preenchida pelo avaliador. 
Os resultados indicam que os autores com maior número de testes aprovados nessa categoria são Carlos Henrique Nunes (seis testes), Claudio Hutz (quatro testes), Luiz Pasquali (três testes) e Ricardo Primi (três testes). A maioria dos testes do Quadro 1 foi aprovada pelo CFP em data anterior a 2013 (73,7\%).

Em relação aos instrumentos destinados à avaliação do construto personalidade por meio de métodos projetivos, o Quadro 2 indica que a maioria dos testes disponíveis são técnicas de manchas (versões dos testes Rorschach ou Zulliger), embora haja diversos instrumentos na lista que podem ser considerados testes expressivos. De acordo com a data de aprovação dos testes pelo CFP, constata-se que seis dos testes listados no Quadro 1 (31,6\%) e cinco dos testes listados no Quadro 2 (35,7\%) foram aprovados nos últimos cinco anos. Os dados indicam ainda que, em cada um desses quadros, há três testes que foram aprovados pelo CFP no ano de 2003. Os autores com maior número de testes projetivos aprovados pelo CFP são Anna Elisa de Villemor-Amaral, Cícero Vaz e Maria Cecília de Vilhena Moraes Silva (três testes cada).

\section{Quadro 2. Informações dos testes de personalidade que utilizam métodos projetivos, considerados favoráveis pelo CFP para avaliação de adultos $(n=14)$.}

\begin{tabular}{|c|c|c|c|c|c|}
\hline Nome do teste & Autores' & Editora & $\begin{array}{c}\text { Idade } \\
\text { indicada }\end{array}$ & $\begin{array}{c}\text { Idade da amostra } \\
\text { normativa }\end{array}$ & $\begin{array}{l}\text { Data da } \\
\text { plenária }\end{array}$ \\
\hline $\begin{array}{l}\text { As Pirâmides } \\
\text { Coloridas de Pfister }\end{array}$ & $\begin{array}{l}\text { Anna Elisa de } \\
\text { Villemor-Amaral }\end{array}$ & $\begin{array}{l}\text { Casa do Psicólogo/ } \\
\text { Pearson }\end{array}$ & $\begin{array}{l}\text { De } 18 \text { a } \\
66 \text { anos }\end{array}$ & De 18 a 66 anos & 22.1 .2005 \\
\hline $\begin{array}{l}\text { HTP: House-Tree- } \\
\text {-Person - Técnica } \\
\text { Projetiva de Desenho }\end{array}$ & $\begin{array}{l}\text { Irai Cristina Boccato } \\
\text { Alves \& Renato } \\
\text { Cury Tardivo }\end{array}$ & Vetor & $\begin{array}{l}\text { A partir de } \\
8 \text { anos }\end{array}$ & Sem acesso & 16.1.2004 \\
\hline $\begin{array}{l}\text { O Método de } \\
\text { Rorschach no Sistema } \\
\text { Compreensivo }\end{array}$ & $\begin{array}{l}\text { Anna Elisa de Villemor- } \\
\text {-Amaral, Antônio } \\
\text { Carlos Pacheco Silva } \\
\text { Neto, \& Regina Sonia } \\
\text { Gattas Fernandes do } \\
\text { Nascimento }\end{array}$ & $\begin{array}{l}\text { Casa do Psicólogo/ } \\
\text { Pearson }\end{array}$ & $\begin{array}{l}\text { A partir de } \\
17 \text { anos }\end{array}$ & De 17 a 59 anos & 25.10 .2003 \\
\hline $\begin{array}{l}\text { O Teste Palográfico } \\
\text { na Avaliação da } \\
\text { Personalidade }\end{array}$ & $\begin{array}{l}\text { Irai Cristina Alves \& } \\
\text { Cristiano Esteves }\end{array}$ & Vetor & $\begin{array}{l}\text { Adolescentes } \\
\text { e adultos }\end{array}$ & De 16 a 52 anos & 3.9 .2004 \\
\hline $\begin{array}{l}\text { Psicodiagnóstico } \\
\text { Miocinético - PMK }\end{array}$ & $\begin{array}{l}\text { Alice Madeleine } \\
\text { Galland de Mira, Luiz } \\
\text { Pasquali, Bartholomeu } \\
\text { Tróccoli, Roberto Cruz, } \\
\text { Jamir Junior \& } \\
\text { Eduardo Legal }\end{array}$ & Vetor & $\begin{array}{l}\text { De } 18 \text { a } \\
70 \text { anos }\end{array}$ & De 18 a 66 anos & 13.10 .2014 \\
\hline Rorschach - Clínico & $\begin{array}{l}\text { Lucia Maria Sálvia } \\
\text { Coelho }\end{array}$ & $\begin{array}{l}\text { Terceira Margem } \\
\text { Editora Didática }\end{array}$ & $\begin{array}{l}\text { De } 16 \text { a } \\
60 \text { anos }\end{array}$ & De 16 a 60 anos & | 3.3.2004 \\
\hline $\begin{array}{l}\text { Rorschach - Sistema } \\
\text { de Escola Francesa }\end{array}$ & Sonia Pasian & $\begin{array}{l}\text { Casa do Psicólogo/ } \\
\text { Pearson }\end{array}$ & Adultos & De 20 a 59 anos & 22.1 .2005 \\
\hline
\end{tabular}


Quadro 2. Informações dos testes de personalidade que utilizam métodos projetivos, considerados favoráveis pelo CFP para avaliação de adultos $(n=14)$.

(conclusão)

\begin{tabular}{|c|c|c|c|c|c|}
\hline Nome do teste & Autores' & Editora & $\begin{array}{l}\text { Idade } \\
\text { indicada }\end{array}$ & $\begin{array}{c}\text { Idade da amostra } \\
\text { normativa }\end{array}$ & $\begin{array}{l}\text { Data da } \\
\text { plenária }\end{array}$ \\
\hline $\begin{array}{l}\text { Rorschach - Teoria e } \\
\text { Desempenho (Sistema } \\
\text { Klopfer) }\end{array}$ & Cícero Vaz & Manole & $\begin{array}{l}\text { De } 18 \text { a } \\
40 \text { anos }\end{array}$ & De 18 a 40 anos & I 2.5.2006 \\
\hline $\begin{array}{l}\text { R-PAS: Sistema de } \\
\text { Avaliação por } \\
\text { Performance no } \\
\text { Rorschach }\end{array}$ & $\begin{array}{l}\text { Fabiano Miguel \& } \\
\text { Danilo Silva }\end{array}$ & Hogrefe Cetepp & Adultos & De 17 a 69 anos & 29.4 .2017 \\
\hline $\begin{array}{l}\text { Técnica de Apercepção } \\
\text { Temática para Idosos - } \\
\text { SAT }\end{array}$ & $\begin{array}{l}\text { Adele de Miguel, Leila } \\
\text { Tardivo, Maria Cecília } \\
\text { Moraes Silva, \& } \\
\text { Silésia Tosi }\end{array}$ & Vetor & $\begin{array}{l}60 \text { anos } \\
\text { ou mais }\end{array}$ & De 60 a 85 anos & 24.5 .2013 \\
\hline $\begin{array}{l}\text { Teste de Apercepção } \\
\text { Temática - TAT }\end{array}$ & $\begin{array}{l}\text { Maria Cecília de } \\
\text { Vilhena Moraes Silva }\end{array}$ & $\begin{array}{l}\text { Casa do Psicólogo/ } \\
\text { Pearson }\end{array}$ & $\begin{array}{l}\text { De } 14 \text { a } \\
40 \text { anos }\end{array}$ & Sem acesso & 25.10 .2003 \\
\hline $\begin{array}{l}\text { Teste de Zulliger no } \\
\text { Sistema Compreensivo: } \\
\text { ZSC - forma individual }\end{array}$ & $\begin{array}{l}\text { Ricardo Primi \& Anna } \\
\text { Elisa de Villemor- } \\
\text {-Amaral }\end{array}$ & $\begin{array}{l}\text { Casa do Psicólogo/ } \\
\text { Pearson }\end{array}$ & $\begin{array}{l}\text { De } 18 \text { a } \\
83 \text { anos }\end{array}$ & De 18 a 83 anos & 31.10 .2008 \\
\hline $\begin{array}{l}\text { Z - Teste - Coletivo e } \\
\text { Individual - Técnica } \\
\text { de Zulliger }\end{array}$ & $\begin{array}{l}\text { Cicero Vaz \& João } \\
\text { Carlos Alchieri }\end{array}$ & Hogrefe Cetepp & $\begin{array}{l}\text { A partir dos } \\
16 \text { anos }\end{array}$ & De 16 a 78 anos & 29.7 .2016 \\
\hline $\begin{array}{l}\text { Z - Teste (Técnica } \\
\text { de Zulliger) }\end{array}$ & Cícero Vaz & Casa do Psicólogo & $\begin{array}{l}\text { De } 16 \text { a } \\
56 \text { anos }\end{array}$ & Sem acesso & 10.12 .2003 \\
\hline
\end{tabular}

1 Embora alguns dos testes listados sejam instrumentos originalmente internacionais, as informações apresentadas na tabela referem-se aos autores dos estudos brasileiros de tradução, adaptação, validação e/ou normatização do teste psicológico em questão.

O Quadro 3 revela que, dos 173 instrumentos que receberam o parecer favorável do CFP, 20 são destinados à avaliação de atributos emocionais ou sociais, o que corresponde a $11,6 \%$ do total. Os construtos mais frequentemente cobertos por esses instrumentos são habilidades sociais, humor (sintomatologia depressiva), agressividade e raiva. A maioria dos testes do Quadro 3 foi aprovada pelo CFP em data anterior a $2013(80 \%)$. Os testes dessa lista são vinculados a seis diferentes editoras atualmente existentes. Os autores com maior número de testes aprovados nessa relação são Makilin Baptista (quatro testes), Luiz Pasquali, Jurema Cunha e Blanca Werlang (dois testes cada). 


\section{Quadro 3. Informações dos testes destinados à avaliação de atributos emocionais/ sociais e considerados favoráveis pelo CFP para avaliação de adultos $(n=20)$.}

\begin{tabular}{|c|c|c|c|c|c|c|}
\hline Nome do teste & Autores' & Editora & $\begin{array}{l}\text { Construto avaliado } \\
\text { segundo o manual }\end{array}$ & $\begin{array}{c}\text { Idade } \\
\text { indicada }\end{array}$ & $\begin{array}{l}\text { Idade da } \\
\text { amostra } \\
\text { normativa }\end{array}$ & $\begin{array}{l}\text { Data da } \\
\text { plenária }\end{array}$ \\
\hline $\begin{array}{l}\text { Entrevista Familiar } \\
\text { Estruturada (EFE) }\end{array}$ & $\begin{array}{l}\text { Terezinha } \\
\text { Férez-Carneiro }\end{array}$ & $\begin{array}{l}\text { Casa do } \\
\text { Psicólogo/ } \\
\text { Pearson }\end{array}$ & $\begin{array}{l}\text { Dinâmica das } \\
\text { relações } \\
\text { familiares }\end{array}$ & $\begin{array}{l}\text { Não consta } \\
\text { (pai, mãe e } \\
\text { filhos) }\end{array}$ & $\begin{array}{l}\text { De } 4 \text { a } \\
49 \text { anos }\end{array}$ & $1^{\circ} .4 .2005$ \\
\hline $\begin{array}{l}\text { Escala Baptista de } \\
\text { Depressão Versão } \\
\text { Adulto - EBADEP - A }\end{array}$ & Makilim Baptista & Vetor & $\begin{array}{l}\text { Humor } \\
\text { (Sintomatologia } \\
\text { depressiva) }\end{array}$ & $\begin{array}{l}\text { De } 17 \text { a } 81 \\
\text { anos }\end{array}$ & $\begin{array}{l}\text { De } 17 \text { a } \\
81 \text { anos }\end{array}$ & 18.11 .2011 \\
\hline $\begin{array}{l}\text { Escala Rathus de } \\
\text { Assertividade }\end{array}$ & $\begin{array}{l}\text { Luiz Pasquali \& } \\
\text { Valdiney Gouveia }\end{array}$ & LabPAM & Assertividade & $\begin{array}{l}\text { Adolescentes } \\
\text { e adultos }\end{array}$ & Sem acesso & 13.9.2003 \\
\hline $\begin{array}{l}\text { Escala de Autenticidade } \\
\text { Agressividade e } \\
\text { Inibição - EdAAl }\end{array}$ & $\begin{array}{l}\text { Cristiane Faiad } \\
\text { de Moura, } \\
\text { Liziane Freitas, \& } \\
\text { Luiz Pasquali }\end{array}$ & LabPAM & $\begin{array}{l}\text { Autenticidade/ } \\
\text { agressividade/ } \\
\text { inibição }\end{array}$ & $\begin{array}{l}\text { Adolescentes } \\
\text { e adultos }\end{array}$ & $\begin{array}{l}\text { De } 19 \text { a } \\
83 \text { anos }\end{array}$ & 27.3.2015 \\
\hline $\begin{array}{l}\text { Escala de Avaliação da } \\
\text { Impulsividade Formas } \\
\text { A e B (EsAvl-A e } \\
\text { EsAvl-B) }\end{array}$ & $\begin{array}{l}\text { Ana Cristina } \\
\text { Ávila-Batista \& } \\
\text { Fabián Rueda }\end{array}$ & Vetor & Impulsividade & $\begin{array}{l}\text { A partir de } \\
18 \text { anos }\end{array}$ & $\begin{array}{l}\text { De } 18 \text { a } \\
41 \text { anos }\end{array}$ & 28.7.20I2 \\
\hline $\begin{array}{l}\text { Escala de Pensamentos } \\
\text { Depressivos - EPD }\end{array}$ & $\begin{array}{l}\text { Adriana Carneiro } \\
\text { \& Makilim } \\
\text { Baptista }\end{array}$ & $\begin{array}{l}\text { Hogrefe } \\
\text { Cetepp }\end{array}$ & $\begin{array}{l}\text { Distorções de } \\
\text { pensamento/ } \\
\text { pensamentos } \\
\text { depressivos }\end{array}$ & $\begin{array}{l}\text { De } 18 \text { a } 59 \\
\text { anos }\end{array}$ & $\begin{array}{l}\text { De } 18 \text { a } \\
59 \text { anos }\end{array}$ & 28.2.20I5 \\
\hline $\begin{array}{l}\text { Escala de Percepção } \\
\text { de Suporte Social - } \\
\text { Adultos (EPSUS-A) }\end{array}$ & $\begin{array}{l}\text { Hugo Cardoso \& } \\
\text { Makilim Baptista }\end{array}$ & $\begin{array}{l}\text { Hogrefe } \\
\text { Cetepp }\end{array}$ & $\begin{array}{l}\text { Suporte social } \\
\text { percebido }\end{array}$ & $\begin{array}{l}\text { De } 18 \text { a } 62 \\
\text { anos }\end{array}$ & $\begin{array}{l}\text { De } 18 \text { a } \\
62 \text { anos }\end{array}$ & 21.9 .2013 \\
\hline $\begin{array}{l}\text { Escala para Avaliação } \\
\text { de Tendência à } \\
\text { Agressividade - EATA }\end{array}$ & $\begin{array}{l}\text { Fermino } \\
\text { Fernandes Sisto }\end{array}$ & $\begin{array}{l}\text { Casa do } \\
\text { Psicólogo/ } \\
\text { Pearson }\end{array}$ & Agressividade & $\begin{array}{l}\text { De } 18 \text { a } 65 \\
\text { anos }\end{array}$ & $\begin{array}{l}\text { De } 18 \text { a } \\
65 \text { anos }\end{array}$ & 26.11 .2010 \\
\hline Escalas BECK & Jurema Cunha & $\begin{array}{l}\text { Casa do } \\
\text { Psicólogo/ } \\
\text { Pearson }\end{array}$ & $\begin{array}{l}\text { Ansiedade/ } \\
\text { depressão/ } \\
\text { desesperança/ } \\
\text { ideação suicida }\end{array}$ & $\begin{array}{l}\text { De } 17 \text { a } 80 \\
\text { anos }\end{array}$ & $\begin{array}{l}\text { De } 17 \text { a } \\
80 \text { anos }\end{array}$ & II.4.2003 \\
\hline $\begin{array}{l}\text { Estilos de Pensar } \\
\text { e Criar }\end{array}$ & Solange Wechsler & $\begin{array}{l}\text { Lamp } \\
\text { PUC- } \\
\text {-Campinas }\end{array}$ & $\begin{array}{l}\text { Estilos de criar e } \\
\text { pensar/ potencial } \\
\text { criativo }\end{array}$ & $\begin{array}{l}\text { De } 17 \text { a } 70 \\
\text { anos }\end{array}$ & $\begin{array}{l}\text { De } 17 \text { a } \\
70 \text { anos }\end{array}$ & $1^{\circ} .12 .2006$ \\
\hline $\begin{array}{l}\text { Inventário de } \\
\text { Depressão de Beck - } \\
\text { BDI-II }\end{array}$ & $\begin{array}{l}\text { Clarice } \\
\text { Gorenstein, Irani } \\
\text { Argimon, Yuan- } \\
\text { Pang Wang, \& } \\
\text { Blanca Werlang }\end{array}$ & $\begin{array}{l}\text { Casa do } \\
\text { Psicólogo/ } \\
\text { Pearson }\end{array}$ & $\begin{array}{l}\text { Sintomatologia } \\
\text { depressiva }\end{array}$ & $\begin{array}{l}\text { Pré- } \\
\text {-adolescentes } \\
\text { até idosos }\end{array}$ & $\begin{array}{l}\text { De } 10 \text { a } \\
\text { "maiores de } \\
60 \text { anos" }\end{array}$ & 26.11 .2010 \\
\hline $\begin{array}{l}\text { Inventário de Estilos } \\
\text { Parentais - IEP }\end{array}$ & Paula Gomide & Vozes & Práticas educativas & $\begin{array}{l}\text { Pais com } \\
\text { filhos acima } \\
\text { de } 5 \text { anos }\end{array}$ & Sem acesso & 2.7 .2005 \\
\hline $\begin{array}{l}\text { Inventário de } \\
\text { Expectativas e Crenças } \\
\text { Pessoais acerca do } \\
\text { Álcool - IECPA }\end{array}$ & $\begin{array}{l}\text { Margareth } \\
\text { Oliveira, Jurema } \\
\text { Cunha, \& Blanca } \\
\text { Werlang }\end{array}$ & $\begin{array}{l}\text { Casa do } \\
\text { Psicólogo/ } \\
\text { Pearson }\end{array}$ & $\begin{array}{l}\text { Expectativas e } \\
\text { crenças acerca } \\
\text { dos efeitos do } \\
\text { álcool }\end{array}$ & $\begin{array}{l}\text { De } 16 \text { a } \\
74 \text { anos }\end{array}$ & Sem acesso & I I.4.2003 \\
\hline
\end{tabular}


Quadro 3. Informações dos testes destinados à avaliação de atributos emocionais/ sociais e considerados favoráveis pelo CFP para avaliação de adultos $(n=20)$.

(conclusão)

\begin{tabular}{|c|c|c|c|c|c|c|}
\hline Nome do teste & Autores' & Editora & $\begin{array}{l}\text { Construto avaliado } \\
\text { segundo o manual }\end{array}$ & $\begin{array}{l}\text { Idade } \\
\text { indicada }\end{array}$ & $\begin{array}{l}\text { Idade da } \\
\text { amostra } \\
\text { normativa }\end{array}$ & $\begin{array}{l}\text { Data da } \\
\text { plenária }\end{array}$ \\
\hline $\begin{array}{l}\text { Inventário de } \\
\text { Expressão de Raiva } \\
\text { como Estado e Traço - } \\
\text { STAXI }\end{array}$ & Ângela Biaggio & Vetor & $\begin{array}{l}\text { Estado de raiva, } \\
\text { traço de raiva, } \\
\text { expressão e } \\
\text { controle de raiva }\end{array}$ & $\begin{array}{l}\text { A partir de } \\
13 \text { anos }\end{array}$ & $\begin{array}{l}\text { De } 16 \text { a } 53 \\
\text { anos }\end{array}$ & 25.10 .2003 \\
\hline $\begin{array}{l}\text { Inventário de } \\
\text { Expressão de Raiva } \\
\text { como Estado e Traço - } \\
\text { STAXI } 2\end{array}$ & $\begin{array}{l}\text { Departamento } \\
\text { de Pesquisas e } \\
\text { Desenvolvimento } \\
\text { Vetor Editora }\end{array}$ & Vetor & $\begin{array}{l}\text { Estado de raiva/ } \\
\text { traço de raiva/ } \\
\text { expressão e } \\
\text { controle de raiva }\end{array}$ & Adultos & $\begin{array}{l}\text { De } 16 \text { a } 63 \\
\text { anos }\end{array}$ & 6.5 .2011 \\
\hline $\begin{array}{l}\text { Inventário de } \\
\text { Habilidades Sociais - } \\
\text { IHS }\end{array}$ & $\begin{array}{l}\text { Zilda Del Prette } \\
\text { \& Almir Del } \\
\text { Prette }\end{array}$ & $\begin{array}{l}\text { Casa do } \\
\text { Psicólogo/ } \\
\text { Pearson }\end{array}$ & $\begin{array}{l}\text { Desempenho/ } \\
\text { habilidades sociais }\end{array}$ & $\begin{array}{l}\text { Jovens e } \\
\text { adultos }\end{array}$ & $\begin{array}{l}\text { De } 15 \text { a } 25 \\
\text { anos }\end{array}$ & II.4.2003 \\
\hline $\begin{array}{l}\text { Inventário de } \\
\text { Habilidades Sociais } \\
\text { Conjugais - IHSC }\end{array}$ & $\begin{array}{l}\text { Miriam Villa \& } \\
\text { Zilda Del Prette }\end{array}$ & $\begin{array}{l}\text { Casa do } \\
\text { Psicólogo/ } \\
\text { Pearson }\end{array}$ & $\begin{array}{l}\text { Habilidades sociais } \\
\text { na conjugalidade }\end{array}$ & $\begin{array}{l}\text { De } 20 \text { a } \\
70 \text { anos }\end{array}$ & $\begin{array}{l}\text { De } 20 \text { a } 73 \\
\text { anos }\end{array}$ & 10.7 .2011 \\
\hline $\begin{array}{l}\text { Inventário de } \\
\text { Percepção de Suporte } \\
\text { Familiar - IPSF }\end{array}$ & Makilin Baptista & Vetor & $\begin{array}{l}\text { Percepção de } \\
\text { afetividade, } \\
\text { autonomia e } \\
\text { adaptação em } \\
\text { relações familiares }\end{array}$ & $\begin{array}{l}\text { De II a } \\
60 \text { anos }\end{array}$ & $\begin{array}{l}\text { De I I a } 57 \\
\text { anos }\end{array}$ & 24.4.2009 \\
\hline $\begin{array}{l}\text { Inventário de Sintomas } \\
\text { de Stress para Adultos } \\
\text { de Lipp - ISSL }\end{array}$ & Marilda Lipp & $\begin{array}{l}\text { Casa do } \\
\text { Psicólogo/ } \\
\text { Pearson }\end{array}$ & $\begin{array}{l}\text { Sintomas de } \\
\text { estresse/fases do } \\
\text { estresse }\end{array}$ & $\begin{array}{l}\text { De } 15 \text { a } \\
75 \text { anos }\end{array}$ & $\begin{array}{l}\text { De I5 a } \\
\text { "maiores de } \\
75 \text { anos" }\end{array}$ & II.4.2003 \\
\hline $\begin{array}{l}\text { Questionário de } \\
\text { Avaliação de } \\
\text { Habilidades Sociais, } \\
\text { Comportamentos e } \\
\text { Contextos para } \\
\text { Universitários (QHC - } \\
\text { UNIVERSITÁRIOS) }\end{array}$ & $\begin{array}{l}\text { Alessandra } \\
\text { Bolsoni-Silva \& } \\
\text { Sônia Loureiro }\end{array}$ & $\begin{array}{l}\text { Hogrefe } \\
\text { Cetepp }\end{array}$ & $\begin{array}{l}\text { Habilidades sociais } \\
\text { de universitários/ } \\
\text { comportamentos } \\
\text { de interação social }\end{array}$ & Universitários & Universitários & 25.10 .2013 \\
\hline
\end{tabular}

' Embora alguns dos testes listados sejam instrumentos originalmente internacionais, as informações apresentadas no quadro referem-se aos autores dos estudos brasileiros de tradução, adaptação, validação e/ou normatização do teste psicológico em questão.

Quanto aos instrumentos destinados à avaliação de construtos relativos à orientação/ao desenvolvimento profissional ou contexto laboral, o Quadro 4 mostra que a maioria desses testes tem sua apresentação em forma de escalas. Os construtos cobertos por esses instrumentos variam entre interesses/perfis profissionais/vocacionais, autoeficácia ou maturidade para escolha profissional, potencial de empregabilidade, apoio social percebido em ambiente laboral, formas de reagir a eventos estressores no trabalho e avaliação de risco de acidentes. Também em relação aos testes dessa categoria, a maioria deles foi aprovada pelo CFP em data anterior a 2013 (83,3\%). A autora com maior número de testes aprovados nessa categoria é Ana Paula Noronha (quatro testes). Seis diferentes editoras constam no Quadro 4. 
Quadro 4. Informações dos testes destinados à avaliação de atributos relacionados à orientação/desenvolvimento profissional ou ao contexto laboral, considerados favoráveis pelo CFP para avaliação de adultos $(n=12)$.

\begin{tabular}{|c|c|c|c|c|c|c|}
\hline Nome do teste & Autores & Editora & $\begin{array}{l}\text { Construto avaliado } \\
\text { segundo o manual }\end{array}$ & $\begin{array}{l}\text { Idade } \\
\text { indicada }\end{array}$ & $\begin{array}{l}\text { Idade da } \\
\text { amostra } \\
\text { normativa }\end{array}$ & $\begin{array}{l}\text { Data da } \\
\text { plenária }\end{array}$ \\
\hline $\begin{array}{l}\text { Avaliação de Interesses } \\
\text { Profissionais - AIP }\end{array}$ & $\begin{array}{l}\text { Denise Bandeira } \\
\text { \& Rosane } \\
\text { Levenfus }\end{array}$ & Vetor & $\begin{array}{l}\text { Interesse } \\
\text { profissional }\end{array}$ & $\begin{array}{l}\text { Adolescentes } \\
\text { e adultos }\end{array}$ & $\begin{array}{l}\text { De } 15 \text { a } \\
39 \text { anos }\end{array}$ & 24.4.2009 \\
\hline $\begin{array}{l}\text { Escala de } \\
\text { Aconselhamento } \\
\text { Profissional - EAP }\end{array}$ & $\begin{array}{l}\text { Ana Paula } \\
\text { Noronha, } \\
\text { Fermino Sisto, \& } \\
\text { Acácia Santos }\end{array}$ & Vetor & $\begin{array}{l}\text { Preferência } \\
\text { para atividades } \\
\text { profissionais }\end{array}$ & $\begin{array}{l}\text { A partir de } \\
17 \text { anos }\end{array}$ & $\begin{array}{l}\text { De } 17 \text { a } \\
73 \text { anos }\end{array}$ & 6.7.2007 \\
\hline $\begin{array}{l}\text { Escala de Autoeficácia } \\
\text { para Escolha } \\
\text { Profissional - EAE - EP }\end{array}$ & $\begin{array}{l}\text { Ana Paula } \\
\text { Noronha e } \\
\text { Rodolfo Ambiel }\end{array}$ & $\begin{array}{l}\text { Casa do } \\
\text { Psicólogo/ } \\
\text { Pearson }\end{array}$ & $\begin{array}{l}\text { Autoeficácia } \\
\text { para escolha } \\
\text { profissional }\end{array}$ & $\begin{array}{l}\text { De } 14 \text { a } \\
21 \text { anos }\end{array}$ & $\begin{array}{l}\text { De } 14 \text { a } \\
21 \text { anos }\end{array}$ & 3.12 .2011 \\
\hline $\begin{array}{l}\text { Escala de } \\
\text { Empregabilidade }\end{array}$ & Keli Campos & Vetor & $\begin{array}{l}\text { Potencial de } \\
\text { empregabilidade }\end{array}$ & $\begin{array}{l}\text { Acima de } \\
18 \text { anos }\end{array}$ & $\begin{array}{l}\text { De } 18 \text { a } \\
66 \text { anos }\end{array}$ & 6.5.20II \\
\hline $\begin{array}{l}\text { Escala de Maturidade } \\
\text { para Escolha } \\
\text { Profissional - EMEP }\end{array}$ & Kathia Neiva & Vetor & $\begin{array}{l}\text { Maturidade } \\
\text { para escolha } \\
\text { profissional }\end{array}$ & $\begin{array}{l}\text { Adolescentes } \\
\text { cursando o } \\
\text { nono ano ou } \\
\text { ensino médio }\end{array}$ & $\begin{array}{l}\text { De } 13 \text { a } \\
\text { I5 anos e de } \\
17 \text { a } 19 \text { anos }\end{array}$ & 22.3 .2014 \\
\hline $\begin{array}{l}\text { Escala de Suporte } \\
\text { Laboral - ESUL }\end{array}$ & $\begin{array}{l}\text { Hugo Cardoso, } \\
\text { Makilim Baptista, } \\
\text { Acácia Santos, \& } \\
\text { Ana Paula } \\
\text { Noronha }\end{array}$ & $\begin{array}{l}\text { Hogrefe } \\
\text { Cetepp }\end{array}$ & $\begin{array}{l}\text { Percepção sobre } \\
\text { o suporte que o } \\
\text { indivíduo percebe } \\
\text { no seu local de } \\
\text { trabalho }\end{array}$ & $\begin{array}{l}\text { De } 17 \text { a } \\
\text { 7I anos }\end{array}$ & $\begin{array}{l}\text { De I7 a } \\
71 \text { anos }\end{array}$ & 30.11 .2013 \\
\hline $\begin{array}{l}\text { Escala de } \\
\text { Vulnerabilidade ao } \\
\text { Estresse no Trabalho - } \\
\text { EVENT }\end{array}$ & $\begin{array}{l}\text { Acácia dos } \\
\text { Santos, Fermino } \\
\text { Sisto, Makilim } \\
\text { Baptista, \& Ana } \\
\text { Paula Noronha }\end{array}$ & Vetor & $\begin{array}{l}\text { Vulnerabilidade } \\
\text { ao estresse ante } \\
\text { as circunstâncias } \\
\text { cotidianas do } \\
\text { trabalho }\end{array}$ & $\begin{array}{l}\text { De } 17 \text { a } \\
54 \text { anos }\end{array}$ & $\begin{array}{l}\text { De } 17 \text { a } \\
54 \text { anos }\end{array}$ & 6.7.2007 \\
\hline $\begin{array}{l}\text { Inventário de Avaliação } \\
\text { Ocupacional - IAO }\end{array}$ & $\begin{array}{l}\text { Ely Garcia \& } \\
\text { Eugênia Sofal }\end{array}$ & SID APA & Perfil ocupacional & $\begin{array}{l}\text { De } 17 \text { a } \\
63 \text { anos }\end{array}$ & $\begin{array}{l}\text { De } 17 \text { a } \\
63 \text { anos }\end{array}$ & 5.9.2008 \\
\hline $\begin{array}{l}\text { Método de Avaliação } \\
\text { de Pessoas - MAPA }\end{array}$ & $\begin{array}{l}\text { Neyde Vieira } \\
\text { Duarte }\end{array}$ & $\begin{array}{l}\text { Neyde } \\
\text { Vieira } \\
\text { Duarte/ } \\
\text { Mapa }\end{array}$ & $\begin{array}{l}\text { Perfil e } \\
\text { competência } \\
\text { comportamental/ } \\
\text { avaliação de risco } \\
\text { de acidente }\end{array}$ & $\begin{array}{l}\text { De } 18 \text { a } \\
6 I \text { anos }\end{array}$ & $\begin{array}{l}\text { De } 18 \text { a } \\
61 \text { anos }\end{array}$ & 3.12 .2011 \\
\hline $\begin{array}{l}\text { Questionário de Busca } \\
\text { Auto-Dirigida - SDS }\end{array}$ & $\begin{array}{l}\text { Ricardo Primi, } \\
\text { Camélia Mansão, } \\
\text { Monalisa Muniz, } \\
\text { \& Maiana Nunes }\end{array}$ & $\begin{array}{l}\text { Casapsi } \\
\text { Livraria e } \\
\text { Editora } \\
\text { Ltda. }\end{array}$ & $\begin{array}{l}\text { Orientação/ } \\
\text { interesse } \\
\text { profissional } \\
\text { (atividades, } \\
\text { competências, } \\
\text { carreira e } \\
\text { habilidades } \\
\text { profissionais) }\end{array}$ & $\begin{array}{l}\text { De } 13 \text { a } \\
68 \text { anos }\end{array}$ & $\begin{array}{l}\text { De } 13 \text { a } \\
68 \text { anos }\end{array}$ & 27.11 .2009 \\
\hline
\end{tabular}


Quadro 4. Informações dos testes destinados à avaliação de atributos relacionados à orientação/desenvolvimento profissional ou ao contexto laboral, considerados favoráveis pelo CFP para avaliação de adultos $(n=12)$. (conclusão)

\begin{tabular}{|c|c|c|c|c|c|c|}
\hline Nome do teste & Autores & Editora & $\begin{array}{l}\text { Construto avaliado } \\
\text { segundo o manual }\end{array}$ & $\begin{array}{l}\text { Idade } \\
\text { indicada }\end{array}$ & $\begin{array}{l}\text { Idade da } \\
\text { amostra } \\
\text { normativa }\end{array}$ & $\begin{array}{l}\text { Data da } \\
\text { plenária }\end{array}$ \\
\hline $\begin{array}{l}\text { Teste de Fotos de } \\
\text { Profissões - BBT-BR }\end{array}$ & $\begin{array}{l}\text { Sonia Pasian, } \\
\text { Renata Assoni, } \\
\text { André Jacquemin, } \\
\text { Erika Okino, } \\
\text { Mariana Noce, \& } \\
\text { Martin Achtinich }\end{array}$ & $\begin{array}{l}\text { Hogrefe } \\
\text { Cetepp }\end{array}$ & $\begin{array}{l}\text { Inclinações } \\
\text { profissionais }\end{array}$ & $\begin{array}{l}\text { A partir de } \\
12 \text { anos }\end{array}$ & $\begin{array}{l}\text { Alunos de } \\
\text { ensino médio } \\
\text { e universitários }\end{array}$ & 12.8.2005 \\
\hline $\begin{array}{l}\text { Teste de Fotos de } \\
\text { Profissões - BBT-BR } \\
\text { Feminino }\end{array}$ & $\begin{array}{l}\text { Sonia Pasian, } \\
\text { Renata Assoni, } \\
\text { André Jacquemin, } \\
\text { Erika Okino, \& } \\
\text { Mariana Noce }\end{array}$ & $\begin{array}{l}\text { Hogrefe } \\
\text { Cetepp }\end{array}$ & $\begin{array}{l}\text { Inclinações } \\
\text { profissionais }\end{array}$ & $\begin{array}{l}\text { A partir de } \\
14 \text { anos }\end{array}$ & $\begin{array}{l}\text { Alunos de } \\
\text { ensino médio } \\
\text { e universitários }\end{array}$ & 13.8.2005 \\
\hline
\end{tabular}

\section{Discussão}

Na lista de testes considerados favoráveis pelo CFP para uso profissional em julho de 2017, os que eram destinados à avaliação de personalidade, atributos emocionais/ sociais e construtos relacionados à orientação profissional ao desenvolvimento de carreira de adultos representaram $37,6 \%$ do total de instrumentos. Os demais instrumentos eram testes destinados à avaliação de crianças e/ou adolescentes ou à avaliação de aspectos cognitivos entre adultos, tendo sido objeto de artigos anteriores (Reppold, Serafini, Ramires et al., 2017; Reppold, Serafini, Gurgel, et al., 2017). O total de testes da lista destinado à avaliação de personalidade em adultos foi $19,1 \%(n=33 / 173)$, sendo maior o número de testes desenvolvidos sob formato de escalas/inventários em relação aos testes projetivos/gráficos/expressivos. O alto percentual de testes destinado à avaliação de personalidade em adultos deve ser interpretado à luz da literatura da área, que indica, em estudos anteriores, que eles eram os mais requisitados nacional e internacionalmente pela comunidade psicológica nas décadas passadas (Noronha et al., 2002) e os mais conhecidos e utilizados pelos psicólogos profissionalmente (Noronha et al., 2003; Noronha, Primi, \& Alchieri, 2005). O elevado número de testes "projetivos/expressivos/gráficos" aprovados pelo CFP chama a atenção e deve ser considerado um avanço para área, à medida que mostra que a complexidade dos métodos projetivos não prescinde do rigor dos estudos de confiabilidade/busca de evidências de validade. Essa oferta viabiliza a utilização de instrumentos que podem qualificar uma avaliação psicodiagnóstica, privilegiando tanto aspectos idiográficos quanto nomotéticos de uma avaliação, devendo assumir-se como complementares aos instrumentos objetivos (Cardoso \& Villemor-Amaral, 2017). 
Quanto às escalas ou aos inventários, Andrade e Salles (2017, p. 15) indicam que eles "são comumente utilizados para a medição de atitudes, interesses e valores cujas respostas não podem ser consideradas certas ou erradas". Entre as escalas/os inventários destinados à avaliação da personalidade, o presente estudo indicou que a maioria era composta de instrumentos de autorrelato (à exceção da Escala Hare PCL-R, preenchida pelo avaliador) e objetivava avaliar múltiplas dimensões do construto e não um único fator. Destaca-se a diversidade teórica dos instrumentos disponíveis. Dos 19 testes listados, oito eram fundamentados teoricamente no modelo dos Cinco Grandes Fatores, considerado, internacionalmente, o principal modelo teórico para os estudos sobre personalidade (Urbina, 2007).

Em relação aos instrumentos destinados à avaliação de atributos afetivos, observa-se que a maior parte dos testes disponíveis é destinada à avaliação de aspectos "negativos", tais como humor/depressão, agressividade e raiva. Essa constatação ilustra uma das preocupações correntes dos processos psicodiagnósticos: uma avaliação ainda centrada em aspectos psicopatológicos ou disfuncionais. Esse foco, no entanto, tem sido questionado por novas perspectivas teóricas, como a Psicologia Positiva, que propõem uma avaliação com foco em forças e virtudes individuais (Reppold, Gurgel, \& Schiavon, 2015).

Quanto à avaliação da indicação de uso dos instrumentos pesquisados, observa-se que a maioria dos testes cobre uma faixa etária ampla da adultez, e muitos são também indicados para pessoas idosas. Ademais, observa-se uma coerência na maior parte dos instrumentos entre a idade indicada no manual para uso e a faixa etária das amostras constituídas para os estudos nacionais de normatização, embora haja dados discordantes em todos os quadros. Essa situação é mais positiva do que a descrita por Reppold, Serafini, Ramires, et al. (2017) em relação aos testes destinados a crianças e/ ou adolescentes considerados favoráveis pelo CFP, na qual várias discrepâncias foram identificadas entre a idade descrita no manual como indicada para uso e a idade das amostras dos estudos normativos brasileiros.

A qualidade das informações consultadas nos testes para adultos é um avanço em relação ao panorama descrito por pesquisadores nas décadas de 1990 e 2000 sobre a qualidade das informações apresentadas pelos manuais dos testes psicológicos então disponíveis (Noronha et al., 2001; Noronha et al., 2003; Pasquali, 1999). A análise publicada por Pasquali (1999) destacava que muitos dos testes disponíveis até início do presente século eram instrumentos internacionais apenas traduzidos para o português. Outros tantos eram instrumentos que não apresentavam, em seus manuais, informações completas sobre suas propriedades psicométricas ou indicações de uso. Esse quadro é ilustrado pelo artigo de Noronha et al. (2004) que revelou que 28,8\% dos testes comercializados até 2003 tinham informações sobre padronização, precisão e validade.

Assim constata-se, com os resultados ora apresentados nesta pesquisa, que os esforços engendrados pelo Satepsi na qualificação dos instrumentos psicológicos, em especial por meio das ações consequentes à Resolução n. 02/2003 do CFP, surtiram 
efeito. Todos os testes aos quais os autores tiveram acesso apresentavam informações sobre autoria e editora e contavam com estudo normativo. De fato, esses são alguns dos critérios mínimos exigidos pelo CFP para disponibilizar os instrumentos ao uso profissional dos psicólogos. Contudo, uma análise qualitativa dos manuais mais recentes permite constatar maior esforço dos autores em apresentar estudos com maior fundamentação teórica e estatística. Ademais, os quadros apresentados no presente estudo revelam o número amplo e crescente de autores e de editoras envolvidos na publicação dos instrumentos psicológicos de uso nacional. Esse avanço da área, ora destacado pelos resultados empíricos, é observado tanto por pesquisadores da área (Noronha \& Reppold, 2010; Primi, 2010) quanto por importantes entidades científicas, como é o caso da American Psychological Association - Division 5 e da ITC (Hutz \& Primi, 2006). No entanto, apesar dos referidos avanços, uma questão polêmica a ser considerada na avaliação do panorama sobre os instrumentos nacionais é a dificuldade de acesso a alguns instrumentos, sobretudo aos instrumentos editados pela LabPAM. Utilizados frequentemente em avaliações de concursos públicos, esses instrumentos são indisponíveis inclusive aos psicólogos.

Por fim, ao concluir que os propósitos do artigo foram contemplados nos resultados apresentados, destaca-se que os quadros também revelam uma situação de alerta para área, quando considerada a data de plenária da aprovação dos instrumentos. Um total de $25 \%$ dos instrumentos favoráveis foi aprovado nos últimos cinco anos. No entanto, vários dos testes atualmente aprovados para uso pelo CFP foram aprovados por plenárias realizadas em 2003, data de início do Satepsi. De acordo com a Resolução n. 006/2004 do CFP, "os dados empíricos das propriedades de um teste psicológico devem ser revisados periodicamente, não podendo o intervalo entre um estudo e outro ultrapassar 15 anos, para os dados referentes à padronização, e 20 anos, para os dados referentes à validade e precisão" (Conselho Federal de Psicologia, 2004, p. 1). Portanto, se não forem submetidos e aprovados novos estudos de padronização, 12 instrumentos incluídos na presente revisão serão considerados desfavoráveis para uso nesse ano, passados os 15 anos de aprovação dos mesmos na plenária. Entre eles, estão alguns instrumentos amplamente utilizados pelos psicólogos. Esse dado reforça a ideia de que o esforço do Satepsi, dos pesquisadores, dos docentes, das editoras e da comunidade em prol da qualificação da área da AP deve ser contínuo e atento às mudanças culturais, instrumentais e teóricas observadas nos últimos anos.

\section{Referências}

Allen, M. J., \& Yen, W. M. (2002). Introduction to measurement theory. Long Grove, IL: Waveland Press.

Ambiel, R. A., Pereira, C. P. da S., \& Moreira, T. da C. (2015). Produção científica em avaliação psicológica no contexto educacional: enfoque nas variáveis socioemocionais. Avaliação Psicológica, 14(3), 339-346. doi:10.15689/ap.2015.1403.05 
Anache, A., \& Correa, F. (2010). As políticas do Conselho Federal de Psicologia para a avaliação psicológica. In Conselho Federal de Psicologia (Org.). Avaliação Psicológica: diretrizes na regulamentação da profissão. Brasília: CFP.

Andrade, J., \& Salles, J. (2017). A diferenciação entre avaliação psicológica e testagem psicológica: questões emergentes. In M. R. C. Lins \& J. C. Borsa, Avaliação psicológica: aspectos teóricos e práticos (Vol. 1), Petrópolis: Vozes.

Bornstein, R. F. (2007). Toward a process-based framework for classifying personality tests: comment on Meyer and Kurtz (2006). Journal of Personality Assessment, 89(2), 202-207. doi:10.1080/00223890701518776

Cardoso, L. M., \& Villemor-Amaral, A. E. (2017). Critérios de cientificidade dos métodos projetivos. In M. R. C. Lins \& J. C. Borsa. Avaliação psicológica: aspectos teóricos e práticos (Vol. 1). Petrópolis: Vozes.

Conselho Federal de Psicologia (2003). Resolução n. 002/2003. Define e regulamenta o uso, a elaboração e a comercialização de testes psicológicos e revoga a Resolução CFP n. 025/2001. Recuperado em 15 de dezembro, 2015, de https://site. cfp.org.br/wp-content/uploads/2012/05/resoluxo022003.pdf

Conselho Federal de Psicologia (2004). Resolução CFP n. 006/2004. Altera a Resolução CFP n. 002/2003. Recuperado em 15 de dezembro, 2015, de https://site.cfp. org.br/wp-content/uploads/2004/06/resolucao2004_6.pdf

Conselho Federal de Psicologia (2012). Resolução CFP n. 005, de 8 de março de 2012. Altera a Resolução CFP n. 002/2003, que define e regulamenta o uso, a elaboração e a comercialização de testes psicológicos. Recuperado em 15 de dezembro, 2015, de https://site.cfp.org.br/wp-content/uploads/2012/03/Resolucao_ CFP_005_12_1.pdf

Conselho Federal de Psicologia (2013). Cartilha Avaliação Psicológica. Brasília: CFP.

Diniz, A. M., Almeida, L. S., \& Pais, L. G. (2007). Contextos profissionais e práticas de avaliação psicológica: Inquérito aos psicólogos portugueses. Psico-USF, 12, 1-12. doi:10.1590/S1413-82712007000100002

Hunsley, J., \& Mash, E. J. (2007). Evidence based assessment. Annual Review of Clinical Psychology, 3, 29-51.doi:10.1146/annurev.clinpsy.3.022806.091419

Hutz, C. S. (2015). O que é avaliação psicológica: métodos, técnicas e testes. In C.S. Hutz, D. R. Bandeira, \& C. M. Trentini (Orgs.). Psicometria. Porto Alegre: Artmed.

Hutz, C. S., \& Primi, R. (2006). Psychological assessment in Brazil: current trends and challenges. The Score (Newsletter APA), 37, 17-18.

International Test Commission (2013). ITC Guidelines on Test Use: Final version. Recuperado em 15 de dezembro, 2018, de https://www.intestcom.org/files/ guideline_test_use.pdf 
Meyer, G. J., \& Kurtz, J. E. (2006). Advancing personality assessment terminology: time to retire "objective" and" projective" as personality test descriptors. Journal of Personality Assessment, 87(3), 223-225. doi:10.1207/s15327752jpa8703_01

Noronha, A. P. P. (2002a). Análise de testes de personalidade: qualidade do material, das instruções, da documentação e dos itens qualidade de testes de personalidade. Estudos de Psicologia, 19(3), 55-65. doi:10.1590/50103-166X2002000300006

Noronha, A. P. P. (2002b). Qualidades psicométricas de instrumentos de avaliação utilizados no contexto educacional. Boletim de Psicologia, 52(117), 129-140.

Noronha, A. P. P., Beraldo, F. N. D. M., \& Oliveira, K. L. D. (2003). Instrumentos psicológicos mais conhecidos e utilizados por estudantes e profissionais de Psicologia. Psicologia Escolar e Educacional, 7(1), 47-56.

Noronha, A. P. P., Freitas, F. D., \& Ottati, F. (2003). Análise de instrumentos de avaliação de interesses profissionais. Psicologia: Teoria e Pesquisa, 19(3), 287-291. doi:10.1590/S0102-37722003000300011

Noronha, A. P. P.; Primi, R., \& Alchieri, J. C. (2004). Parâmetros psicométricos: uma análise de testes psicológicos comercializados no Brasil. Psicologia Reflexão e Crítica, 24(4), 88-99. doi:10.1590/\$1414-98932004000400011

Noronha, A. P. P., Primi, R., \& Alchieri, J. C. (2005). Instrumentos de avaliação mais conhecidos/utilizados por psicólogos e estudantes de psicologia. Psicologia: Reflexão e Crítica, 18(3), 390-401. doi:10.1590/\$0102-79722005000300013

Noronha, A. P. P., \& Reppold, C. T. (2010). Considerações sobre a avaliação psicológica no Brasil. Psicologia: Ciência e Profissão, 30(Esp.), 192-201. doi:10.1590/S14 14-98932010000500009

Noronha, A. P. P., Sartori, F. A., Freitas, F. A., \& Ottati, F. (2001). Informações contidas nos manuais de testes de inteligência publicados no Brasil. Psicologia em Estudo, 6(2), 101-106. doi:10.1590/S1413-737222001000200014

Noronha, A. P. P., Sartori, F. A., Freitas, F. A., \& Ottati, F. (2002). Informações contidas nos manuais de testes de personalidade. Psicologia em Estudo, 7(1), 143-149. doi:10.1590/S1413-73722002000100017

Pasquali, L. (1999). Instrumentos psicológicos: manual prático de elaboração. Brasília: LabPAM, Ibapp.

Primi, R. (2010). Avaliação psicológica no Brasil: fundamentos, situação atual e direções para o futuro. Psicologia: Teoria e Pesquisa, 26(25 anos), 25-36. doi:10.1590/ S0102-37722010000500003

Reppold, C. T., Gurgel, L. G., \& Schiavon, C. C. (2015). Research in Positive Psychology: a systematic literature review. Psico-USF 20(2), 275-285. doi:10.1590/1413-827 12015200208 
Reppold, C. T., \& Serafini, A. J. (2010). Novas tendências no ensino da avaliação psicológica. Avaliação Psicológica, 9(2), 323-329.

Reppold, C. T., Serafini, A. J., Gurgel, L. G., \& Kaiser, V. (2017). Avaliação de aspectos cognitivos em adultos: análise de manuais de instrumentos aprovados. Avaliação Psicológica, 16(2), 137-144. doi:10.15689/AP.2017.1602.03

Reppold, C. T., Serafini, A. J., Ramires, D. A., \& Gurgel, L. G. (2017). Análise dos manuais psicológicos aprovados pelo SATEPSI para avaliação de crianças e adolescentes no Brasil. Avaliação Psicológica, 16(1), 19-28. doi:10.15689/ap.2017. 1601.03

Santos, A. M. D., Anache, A. A., \& Santana, R. C. D. (2015). Overview of Brazilian Scientific Production in Psychological Evaluation. Psico-USF, 20(3), 547-559. doi:10.1590/1413-82712015200315

Serafini, A. J., Budzyn, C. S., \& Fonseca, T. L. R. (2017). Tipos de testes: características e aplicabilidade. In M. R. C. Lins \& J. C. Borsa. Avaliação psicológica: aspectos teóricos e práticos (Vol. 1). Petrópolis: Vozes.

Urbina, S. (2007). Fundamentos da testagem psicológica. Porto Alegre: Artmed.

Wagner, E. E. (2008). Beyond "objective" and "projective": a logical system for classifying psychological tests: comment on Meyer and Kurtz (2006). Journal of Personality Assessment, 90(4), 402-405. doi:10.1080/00223890802108246

\section{Nota dos autores:}

Agradecemos a Ana Elisa Salomão Bosquê, Daniely Simão Pereira, Lucila Moraes Cardoso e Ana Cristina Resende a colaboração no acesso aos dados, e ao Conselho Nacional de Desenvolvimento Científico e Tecnológico (CNPq), o apoio à pesquisa.

Submissão: 21.12.2015

Aceite: 27.7 .2018 